Brenda Banwell, MD

Douglas L. Arnold, MD

Jan-Mendelt Tillema, MD

Maria A. Rocca, MD

Massimo Filippi, MD

Bianca Weinstock-

Guttman, MD

Robert Zivadinov, MD, $\mathrm{PhD}$

Maria Pia Sormani, PhD

Correspondence to

Dr. Banwell:

banwellb@email.chop.edu

\title{
MRI in the evaluation of pediatric multiple sclerosis
}

\section{ABSTRACT}

MRI plays a pivotal role in the diagnosis of multiple sclerosis (MS) in children, as it does in adults. The presence of multiple lesions in CNS locations commonly affected by MS, along with the presence of both enhancing and nonenhancing lesions, can facilitate a diagnosis of MS at the time of a first attack, whereas the accrual of serial lesions or new clinical attacks over time confirms the diagnosis in patients not meeting such criteria at onset. T2 and enhancing lesion accrual could serve as a primary outcome metric for pediatric MS clinical trials of selected therapies with anti-inflammatory activity in order to facilitate feasible trial size numbers. More-advanced MRI techniques reveal the impact of MS on tissue integrity within both T2-bright and T1hypointense lesions and regions of normal-appearing tissue. Volumetric MRI analyses quantify the impact of MS on age-expected brain growth, and fMRI reveals activation and resting-state functional connectivity patterns in patients with pediatric MS that differ from those seen in healthy age-matched youth. Such studies are of critical importance because MS onset during childhood may profoundly influence maturing and actively myelinating neural networks. Highfield MRI visualizes MS pathology at a near-microscopic level and has the potential to more fully explain mechanisms for cognitive impairment, fatigue, and disability in patients with pediatric MS. Neurology ${ }^{\circledR}$ 2016;87 (Suppl 2):S88-S96

\section{GLOSSARY}

ADEM = acute disseminated encephalomyelitis; $\mathbf{C I S}=$ clinically isolated syndrome; DIS = dissemination in space; DIT = dissemination in time; DTI = diffusion tensor imaging; IPMSSG = International Pediatric MS Study Group; $\mathbf{M S}=$ multiple sclerosis; $\mathbf{M T}$ = magnetization transfer; $\mathbf{R I S}$ = radiologically isolated syndrome; $\mathbf{R R M S}$ = relapsing-remitting MS

Multiple sclerosis (MS) in childhood and adolescence is characterized by both clinical and MRI evidence of highly active inflammation. Although many aspects of relapsing-remitting MS (RRMS) are similar in both pediatric- and adult-onset disease, very young pediatric patients have certain unique features. Disorders to consider in the differential diagnosis of MS include nonMS inflammatory diseases, CNS involvement in systemic inflammatory disorders, and genetic and metabolic disorders of white matter, some of which have an associated inflammatory response. MRI forms a key component in evaluation. Pediatric-onset MS also provides a window into understanding the earliest biological aspects of MS. The disease has a great impact on brain integrity, as evidenced by MRI metrics that quantify disruption of tissue microstructure as well as loss of age-expected brain volume. The present article focuses on recent advances in neuroimaging in pediatric MS, with practical considerations for the use of MRI in diagnosis, monitoring of clinical course, and response to therapy. Potential advanced imaging techniques to further understand the impact of the disease on the ongoing maturing CNS are discussed, as is the utility of MRI as an outcome measure for clinical trials in pediatric MS.

ROLE OF MRI IN MS DIAGNOSIS Considerable recent effort has focused on the contributions of MRI for distinguishing children with MS from children with monophasic demyelination. Other articles in this supplement provide details regarding the clinical features of incident demyelination, including acute disseminated

From The Children's Hospital of Philadelphia (B.B.) Perelman School of Medicine, University of Pennsylvania; McConnell Imaging Center (D.L.A.), McGill University, Montreal, Quebec, Canada; Mayo Clinic (J.-M.T.), Rochester, MN; Neuroimaging Research Unit (M.A.R., M.F.), Institute of Experimental Neurology, San Raffaele Scientific Institute, "Vita-Salute" San Raffaele University, Milan, Italy; State University of New York at Buffalo (B.W.-G., R.Z.); and Department of Health Sciences (M.P.S.), University of Genoa, Italy.

Go to Neurology.org for full disclosures. Funding information and disclosures deemed relevant by the authors, if any, are provided at the end of the article. 
encephalomyelitis (ADEM) and clinically isolated syndromes (CIS; which include optic neuritis, transverse myelitis, brainstem or cerebellar symptoms, and other CNS presentations). MRI features that help identify children for whom CIS represents the first attack of MS include 1 or more nonenhancing T1-hypointense lesions, 2 or more periventricular lesions, and the absence of a diffuse lesion distribution pattern. Two of these 3 criteria were described to be sensitive for distinguishing MS from ADEM. ${ }^{1}$ Subsequently, a large population-based study revealed that the highest odds ratio for subsequent MS diagnosis was the presence of both 1 periventricular T2-hyperintense lesion and at least 1 T1-hypointense lesion. ${ }^{2} \mathrm{~T} 1$ hypointense lesions are detected in fewer than $20 \%$ of patients with ADEM. ${ }^{3}$ In children with a non-ADEM presentation, a normal brain MRI at onset (such as can be seen in children with optic neuritis or transverse myelitis) conveys a very low $(<3 \%)$ likelihood of MS diagnosis. ${ }^{2}$

The current MRI criteria for MS (2010 McDonald $)^{4}$ include a specific focus on pediatric features, unlike prior MS diagnostic criteria that did not address pediatric MS. The 2010 McDonald criteria were designed to simplify the requirements for dissemination in space (DIS) and time (DIT), thereby improving early detection of MS while maintaining specificity.

DIS in both pediatric and adult patients with MS is met by the presence of at least 1 lesion in at least 2 of 4 typical white matter locations, including juxtacortical, periventricular, infratentorial, and spinal cord. In patients presenting with a spinal cord or brainstem syndrome, these symptomatic lesions do not count toward the lesion count. ${ }^{4}$

DIT has unique considerations in the pediatric population. In older patients ( $\geq 12$ years of age), it can be met at the time of a baseline scan provided there is evidence of both a gadolinium-enhancing and nonenhancing clinically silent lesion, based on prior work showing that the presence of nonenhancing and asymptomatic gadolinium-enhancing lesions is predictive for the development of RRMS in the setting of a first clinical attack. ${ }^{5,6} \mathrm{New}$ lesions on serial scans, or further clinical attacks, are also sufficient for MS diagnosis in patients not meeting criteria at the time of their incident attack and serial clinical and MRI evaluations are advised when confirming the diagnosis of MS in patients with onset age younger than 12 years.

The clinical and imaging behavior of the disease in adolescent patients has significant similarities to adult-onset RRMS, and pediatric patients have comparable total T2 lesion burden to adult-onset patients when matched for disease duration. ${ }^{7,8}$ In children younger than 12 years, lesions tend to be larger than typical adult lesions, with less well-defined margins, ${ }^{9,10}$ and lesions may completely resolve early in the disease, which is rare in adult-onset MS. ${ }^{10}$ In younger children, the 2010 criteria are less reliably predictive of confirmed relapsing MS, ${ }^{11}$ and distinguishing MS from monophasic demyelination can be more difficult than in adolescent patients. The 2010 criteria specifically preclude adjudication of DIS and DIT at the time of an acute attack if the attack meets criteria for $\mathrm{ADEM}^{4}$ and require that MS diagnosis in such children be predicated on serial evidence of nonADEM attacks and/or accrual of clinically silent new lesions. Overall, the $2010 \mathrm{McD}$ onald criteria have been shown to perform better than or similar to previously proposed pediatric MS criteria. ${ }^{12-17}$ and have been incorporated into the revised International Pediatric MS Study Group (IPMSSG) 2013 diagnostic criteria for pediatric MS. ${ }^{18}$

The spinal cord is 1 of the 4 DIS locations in the McDonald 2010 criteria, although a recent study suggested inclusion of spinal cord imaging at first attack did not improve diagnostic identification of children with MS. ${ }^{16}$ In general, spinal lesions in patients with pediatric MS have similar imaging characteristics as those in adult patients. ${ }^{19}$ Although most lesions in patients with MS are relatively small, longitudinally extensive lesions spanning greater than 3 spinal segments in length have been described in ADEM and neuromyelitis optica and in up to $10 \%$ of patients with pediatric MS. ${ }^{20}$ In view of time constraints with sedation and availability of MRI, not all children receive brain and spinal cord MRI at baseline. Including spinal cord MRI can provide a more comprehensive assessment in cases in which there is diagnostic uncertainty and could provide important information for future assessments. The accrual of clinically silent new spinal lesions occurs in 25\% of patients with adult-onset MS in the first few years of RRMS, suggesting that spinal cord imaging may be of value in monitoring disease activity in pediatric MS as well. ${ }^{21}$ However, as of yet, the frequency of clinically silent lesions and the relationship between spinal cord lesions and clinical outcome has not been well-studied in pediatric MS. Given that the majority of spinal lesions in patients with pediatric MS occur in the cervical and thoracic cord, ${ }^{19}$ spinal imaging of the cervical and thoracic spine would have the highest diagnostic value.

MRI features consistent with MS have been found in children imaged for indications other than clinical demyelination. The term radiologically isolated syndrome (RIS) has been coined for such circumstances. At present, children and adults with RIS, even those who show new lesions on serial imaging, do not meet criteria for MS unless a clinical attack occurs. It is important to perform paraclinical testing to evaluate 
for subclinical disease or for evidence of a prior attack that was not identified - a key issue in young children who may not have reported mild symptoms. Visualevoked responses ${ }^{22}$ or optical coherence tomography features ${ }^{23,24}$ consistent with prior optic neuritis can be used to support a prior demyelinating event, which in combination with MRI evidence of DIT and DIS can confirm the diagnosis of MS. Further research on the implications of RIS in the pediatric population and consensus regarding management of both children and adults with accrual of new MRI lesions is required.

Differential diagnosis, special considerations, and unique imaging features. Table 1 summarizes key imaging features of MS, ADEM, other inflammatory CNS disorders, and selected metabolic and genetic disorders associated with inflammatory features. Moredetailed reviews of metabolic and genetic white matter disease of children have been recently published (http://www.ncbi.nlm.nih.gov/books/ NBK184570). ${ }^{25,26}$ Distinguishing demyelinating disease from these inherited conditions can be challenging, and the MRI appearance can guide further diagnostic studies based on the imaging pattern. Some typical MRI appearances that would raise the consideration of several of these disorders are listed in table 1 and included in the figure.

STANDARDIZED MRI SEQUENCES AND MRI CONSIDERATIONS FOR MULTICENTER RESEARCH In adult MS studies, and clinical trials in particular, rigorous standards for image acquisition have proven pivotal in order to (1) ensure reproducibility of MRI endpoints, (2) permit multisite comparisons and grouping of multisite data, and (3) permit serial measures of lesional or tissue volumes. Standardized 2- or 3-dimensional $\mathrm{T} 1$ and $\mathrm{T} 2$ images with consistent orientation (axial, sagittal, coronal) of each sequence permit far more accurate visualization of new or enlarging lesions. Field strength, slice thickness, gap, and angulation can influence new lesion detection. ${ }^{27}$ For research, it is imperative to adhere to rigorous and standardized imaging protocols and to ensure quality testing of each MRI scanner.

Field strength affects both quantitative and qualitative measurements of both brain volumes and lesions. The effect of gadolinium on T1 relaxation increases with increasing field strength. Thus, gadolinium-enhancing lesion counts are greater at $3 \mathrm{~T}$ than at $1.5 \mathrm{~T} .{ }^{28} \mathrm{~T} 2$-weighted lesion detectability is also increased at $3 \mathrm{~T}$ compared to $1.5 \mathrm{~T}$ because of improvements in signal-to-noise ratio and the potential reductions in slice thickness and gaps. However, in terms of confirming DIS in MS diagnostic evaluations, 1.5T MRI and 3T MRI have been found to be comparable in adults. ${ }^{29}$ Ultra-high-field MRI (7T) and specific sequences on $3 \mathrm{~T}$ permit visualization of cortical lesions that are otherwise invisible on $1.5 \mathrm{~T}$.

\section{USE OF MRI IN CLINICAL PRACTICE The IPMSSG} proposed guidelines for monitoring clinical disease activity in pediatric patients, ${ }^{30}$ which suggest that brain MRI every 6 months is a reasonable frequency for assessing subclinical accrual of new disease. The first brain MRI after initiation of a new therapy is also proposed to occur at 6 months in order to avoid prematurely adjudicating treatment failure for therapies that require time for maximal efficacy. Clinical scans are valuable for detecting new and enlarging lesions and lesion enhancement. Recent concerns regarding CNS accumulation of gadolinium has prompted use of newer agents, and further information on the safety of paramagnetic agents is required. ${ }^{31-33}$ Given the potential concerns regarding accumulation of gadolinium in the brain over time, it is reasonable to consider whether administration of contrast is required for all serial MRI studies. Gadolinium-enhanced images play a key role at onset and on serial MRI scans obtained to confirm MS diagnosis. ${ }^{4}$ It could be argued that once the diagnosis is confirmed and serial imaging is obtained to monitor disease activity (and response to therapy), enhanced images are required only if the $\mathrm{T} 2$ images demonstrate new lesions, in order to then determine whether these new lesions also enhance. The presence of new enhancing lesions has been shown to correlate with relapse rate in adults, ${ }^{34}$ and the presence of enhancing lesions on serial MRI studies is one factor proposed for consideration when adjudicating inadequate treatment response in patients with pediatric MS. ${ }^{30}$ If serial MRI scans do not have new T2 lesions, gadolinium administration is not required. Radiologist interpretation of the T2 lesion pattern while the MRI was being acquired would be required, which may not be possible in all circumstances.

\section{ADVANCED MRI TECHNIQUES AND THEIR USE IN} PEDIATRIC MS Advanced MRI techniques include magnetization transfer (MT) imaging, diffusion tensor imaging (DTI), fMRI, and 2- or 3-dimensional T1- and T2-weighted sequences designed to permit quantification of regional and whole brain as well as T2 and T1 lesion volumes. Table 2 summarizes these techniques and the findings of each in pediatric MS cohorts to date.

The goal of advanced imaging is to provide a more "pathologic" insight that in turn will relate more directly to clinical outcomes. As referenced in table 2, the extent of intralesional increase in MT ratio is considered indicative of remyelination and repair. Abnormalities in DTI metrics indicate loss of 
Table 1 Role of MRI in the differential diagnosis of MS in children

\begin{tabular}{|c|c|c|c|c|}
\hline Disorder & T2 lesion patterns & T1 lesion patterns & Gd+ & Other \\
\hline \multirow[t]{5}{*}{$M^{2,4,18,45}$} & Multifocal & $\begin{array}{l}\geq 1 \text { T1-hypointense } \\
\text { lesion }\end{array}$ & Typically present at onset & LETM occurs in $10 \%$ \\
\hline & $\geq 1 \mathrm{PV}$ lesion & $\begin{array}{l}\text { Lesions accrue over } \\
\text { time }\end{array}$ & & T2 lesions are not symmetric \\
\hline & $1 \mathrm{JC}$ lesion & & & \\
\hline & 1 BStem lesion & & & \\
\hline & Lesions perpendicular to long axis of $\mathrm{CC}$ & & & \\
\hline \multirow[t]{3}{*}{$\mathrm{ADEM}^{1-3,46}$} & Multifocal & Rare (<20\%) & Variable and can be absent & $\begin{array}{l}\text { LETM common in patients with } \\
\text { cord involvement }\end{array}$ \\
\hline & III-defined borders & & & \\
\hline & Rapid resolution after corticosteroids & & & \\
\hline \multirow[t]{4}{*}{ NMOSD $^{48}$} & $\begin{array}{l}\text { ON lesions (often extensive, } \\
\text { often chiasmal) }\end{array}$ & $\begin{array}{l}\text { T1 hypointensity } \\
\text { occurs in chronic } \\
\text { lesions }\end{array}$ & $\mathrm{Gd}+\mathrm{ON} /$ chiasm & $\begin{array}{l}\text { Accrual of subclinical lesions appears } \\
\text { to be rare but not well-studied }\end{array}$ \\
\hline & LETM & & & \\
\hline & Diencephalic lesions & & Spotty Gd+ cord & \\
\hline & ADEM-like pattern in some & & & \\
\hline \multirow[t]{2}{*}{$\begin{array}{l}\text { Isolated CNS } \\
\text { vasculitis }^{49,50}\end{array}$} & III-defined lesions & $\begin{array}{l}\text { T1 lesions occur with } \\
\text { variable frequency }\end{array}$ & Meningeal enhancement & MRA normal \\
\hline & Can involve $\mathrm{ON}$ and cord & & $\begin{array}{l}\text { Cortical lesion } \\
\text { enhancement }\end{array}$ & Cerebral angiogram normal \\
\hline \multirow{3}{*}{$\begin{array}{l}\text { Mitochondrial } \\
\text { disease }^{54}\end{array}$} & Lesions tend to be symmetric & Small cystlike lesions & & Often systemic features \\
\hline & $\begin{array}{l}\text { Often involve deep gray nuclei, olivary nuclei, } \\
\text { and periaqueductal gray }\end{array}$ & & & Short stature \\
\hline & $\begin{array}{l}\text { "Strokelike" lesions that do not } \\
\text { conform to vascular distribution }\end{array}$ & & & \\
\hline \multirow[t]{3}{*}{ DARS2 $2^{55-57}$} & T2 lesions in ST, PV, and deep WM & & Cord and Bstem lesions & MRS lactate in areas of abnormal WM \\
\hline & Lesions in post limb IC, medulla, CN V nerves & & & \\
\hline & $\begin{array}{l}\text { Cord lesions in dorsal columns and lateral CS } \\
\text { tracts }\end{array}$ & & & \\
\hline
\end{tabular}

Abbreviations: $\mathrm{Ab}=$ antibody; $\mathrm{ADEM}=$ acute disseminated encephalomyelitis; Bstem = brainstem; $\mathrm{CC}=$ corpus callosum; $\mathrm{CN}=\mathrm{cranial}$ nerve; $\mathrm{CS}=$ corticospinal; $\mathrm{Gd}$ = gadolinium; HLH = hemophagocytic lymphohistiocytosis; IC = internal capsule; JC = juxtacortical; LETM = longitudinally extensive transverse myelitis; MOG = myelin oligodendrocyte glycoprotein; MRA = magnetic resonance angiogram; MRS = magnetic resonance spectroscopy; MS = multiple sclerosis; NMOSD = neuromyelitis optica spectrum disorder; ON = optic nerve; PV = periventricular; $\mathrm{ST}=$ supratentorial; WM = white matter.

microstructural integrity in both lesional as well as normal-appearing tissue. Differences in fMRI brain activation patterns both at rest and during tasks between patients with MS and controls is emerging as evidence of either increased activation of compensatory networks in cognitively preserved patients or as failure of activation of key regions in patients with cognitive impairment. Age- and sex-normative data for all of these modalities are critical.

Quantitative MRI analyses in patients with pediatric MS have provided compelling evidence that the young age of children with MS is not protective against T2- and T1-weighted lesion accrual. Of perhaps even greater importance is the negative impact 

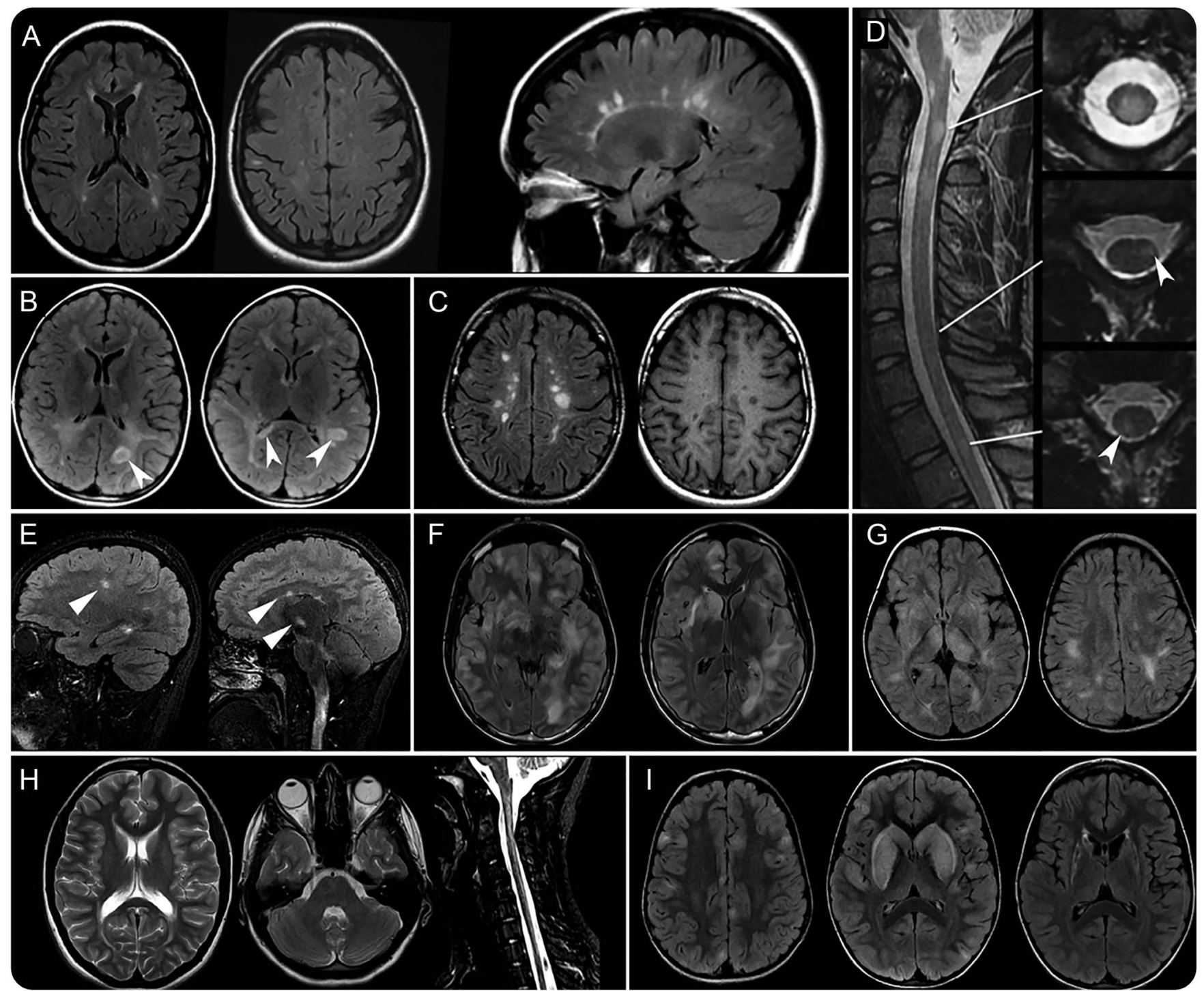

Examples of typical demyelinating lesions of pediatric multiple sclerosis (MS). Panels A-D show typical pediatric MS lesions and panels E-I show other differential diagnostic considerations. (A) Typical periventricular and juxtacortical lesions on axial fluid-attenuated inversion recovery (FLAIR) images in an adolescent patient. Sagittal image shows typical periventricular ovoid shape (Dawson fingers). (B) Axial FLAIR images of a prepubescent patient with large confluent (older) lesions. These are bilaterally present in a predominantly periventricular distribution and have a clear multifocal distribution without symmetry in shape. Multifocal large new lesions (arrowheads) have a more distinct border. (C) T1 hypointensities shown on right image, with not all white matter lesions seen on same level axial FLAIR image revealing T1-hypointense signal change. (D) Spinal cord MRI with sagittal T2-weighted image on the left and axial image at 3 levels on the right. Lesions are often visible on sagittal images but can be missed given small lesion size and slice thickness. Higher-resolution axial slices can assist with identifying typical demyelinating lesions, as shown on the 3 panels on the right (arrowheads pointing to smaller lateral and laterodorsal lesions not clearly visible on sagittal image). (E) Adolescent patient with transverse myelitis with longitudinally extensive spinal cord lesion. On sagittal FLAIR images the cranial portion of this extensive spinal cord lesion is visible (longitudinally extensive with caudal end of lesion at T8 [not shown]). There are multiple nonenhancing hyperintense lesions (arrowheads) within the white matter in a circumventricular pattern, including lesions in the corpus callosum. Aquaporin-4-lgG testing was positive, confirming the diagnosis of neuromyelitis optica. (F) Adolescent patient who presented initially with focal seizures, subsequently had transverse myelitis, and during course of workup developed encephalopathy and optic neuritis. MRI showed rapid succession with increasing areas of widespread multifocal T2-hyperintense signal change affecting white matter, spinal cord, and cortical and deep gray matter. Biopsy was consistent with small vessel vasculitis. (G) Multifocal white matter and cortical and deep gray matter involvement (thalamus) in a patient presenting with multifocal deficits and encephalopathy leading to a diagnosis of acute disseminated encephalomyelitis. (H) Fifteen-year-old patient with DARS mutations demonstrating mild periventricular white matter changes and longitudinally extensive signal abnormality in the posterior cervical cord (images courtesy of Dr. A. Vanderver, National Children's Medical Center, Washington, DC). (I) Patient presented with focal seizures, encephalopathy, dysarthria, and dystonia mixed with hyperkinetic movement disorder consistent with a presumed mitochondrial encephalopathy exacerbated in setting of recent infection and vaccination. There are striking bilateral changes in the striatum with nonenhancing T2-hyperintense signal change. Follow-up imaging (right image) shows significant atrophy, consistent with striatal necrosis (images courtesy of Dr. M.C. Patterson, Mayo Clinic, Rochester, MN).

of MS onset during childhood on age-expected brain growth and the alarming onset of brain atrophy in adolescents. ${ }^{35,36}$
Serial analyses for brain volume change and importance of normative data. Unlike in patients with adult-onset MS, in pediatric patients with MS age-expected brain 
Table 2 MRI techniques and their contribution to pediatric MS research

\begin{tabular}{|c|c|}
\hline Technique & Measure \\
\hline \multirow[t]{3}{*}{ T2-PD and T1 lesion imaging 8,40} & Standardized T2/PD and T1 sequences \\
\hline & Postprocessing pipeline to create lesion maps \\
\hline & $\begin{array}{l}\text { Computerized quantification of total T2 and } \\
\text { T1 lesion volumes }\end{array}$ \\
\hline \multirow[t]{4}{*}{ 3D-T1 imaging $35,36,58,59$} & High-resolution, isotropic, T1-weighted sequences \\
\hline & Postprocessing pipeline to create tissue map \\
\hline & Calculation of total brain and regional brain volumes \\
\hline & $\begin{array}{l}\text { Serial measures require growth trajectory modeling and } \\
\text { comparison to age- and sex-normative growth curves }\end{array}$ \\
\hline \multirow[t]{3}{*}{$M T^{8,60-62}$} & Calculates an index, the MTR \\
\hline & $\begin{array}{l}\text { MTR }=\downarrow \text { ability of protons bound to the brain tissue } \\
\text { matrix to exchange magnetization with the surrounding } \\
\text { free water = marker of tissue disruption }\end{array}$ \\
\hline & Longitudinal within lesion $\uparrow \mathrm{MTR}=$ remyelination \\
\hline \multirow[t]{2}{*}{ DTI $43,62-67$} & $\begin{array}{l}\text { Sensitive to the orientation and density of cellular } \\
\text { structures hindering water diffusion }\end{array}$ \\
\hline & $\begin{array}{l}\text { FA and } \uparrow M D \text { reflect loss of tissue microstructural } \\
\text { integrity }\end{array}$ \\
\hline
\end{tabular}

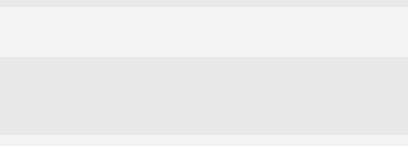

$\mathrm{fMRI}^{63,68-71} \quad$ Patterns of cerebral blood flow indicate patterns of activation and/or FC

Measures resting-state (i.e., default-mode and salience networks) and task-based activation

\section{Findings in pediatric MS}

Pediatric MS patients have $>$ total T2 lesion volumes, $>$ T1 lesion volume, and $>$ infratentorial lesion volumes relative to disease-duration-matched adult-onset MS patients

T2 lesion volume correlates with decreased cognitive performance

T1 lesion volume does not correlate with cognition, but total T1 volumes are low

Pediatric MS patients have smaller head sizes vs $\mathrm{HC}$

Whole-brain volume, and to a greater extent normalized thalamic volumes, are significantly smaller in pediatric MS vs $\mathrm{HC}$

Pediatric MS patients do not demonstrate age-expected brain growth, do not reach maturational maximal brain volumes, and show brain atrophy in adolescence

No difference in MTR of NAWM in pediatric MS vs HC

Younger pediatric MS patients show greater MTR recovery within lesions compared to older adolescents

NAWM damage ( $\downarrow F A, \uparrow M D)$ occurs early in pediatric MS; deep gray matter appears spared

WM integrity disruption is widespread, including NAWM

Degree of FA and MD change is influenced by T2 lesion volume

FA in corpus callosum and total WM correlates with $\downarrow$ processing speed and with overall $\downarrow$ cognitive performance

DTI abnormalities are not detected in NAWM in children with monophasic demyelination

Pediatric MS patients differ from HCs in resting-state FC of posterior brain regions of the default mode network

Motor network recruitment during active fMRI tasks similar between pediatric MS patients and $\mathrm{HC}$

Activation patterns and their relationship to cognitive function are under active study

Abbreviations: $\mathrm{DTI}=$ diffusion tensor imaging; $\mathrm{FA}=$ fractional anisotropy; $\mathrm{FC}=$ functional connectivity; $\mathrm{HC}=$ healthy controls; $\mathrm{MD}=$ mean diffusivity; $\mathrm{MS}=$ multiple sclerosis; MT = magnetization transfer; MTR = magnetization transfer ratio; NAWM = normal-appearing white matter; $\mathrm{PD}=$ proton density; $\mathrm{WM}=$ white matter.

and skull growth complicates the interpretation of volume changes over time. Normalization of brain size to skull size, which is used routinely in adults to reduce population variance, is not appropriate in children because the growth of brain and skull dissociates to a small but significant extent, making skull-based normalization unreliable. Changes in brain volume in children have to be interpreted in the context of age-expected brain growth using growth trajectory modeling. ${ }^{36}$ Normative data should be obtained using the same standardized pulse sequences.

MRI AS AN OUTCOME IN CLINICAL TRIALS The relatively small number of patients with pediatric MS challenges the feasibility of clinical trials in this population, especially if these trials are attempting to achieve statistical power with clinical endpoints as primary outcomes. The first clinical trials in pediatric MS cohorts are now under way. Although surrogacy of MRI lesion activity for relapses is more controversial at the individual level, ${ }^{37,38}$ the role of lesion accrual as a surrogate in clinical trials of the therapies tested in adult MS has been demonstrated. ${ }^{34,39}$ A recent meta-analysis ${ }^{39}$ demonstrated a specific and predictable correlation between the effect of treatments on MRI lesions and the effect of treatments on clinical relapse rates in patients with RRMS. It is well known that the validity of a surrogate endpoint is treatment-specific, so it should not be assumed that the effect of a drug with a new and unknown mechanism of action on relapses can be fully estimated by its effect on MRI lesions. However, it is reasonable to assert that MRI is an acceptable surrogate outcome in pediatric clinical trials of therapies already approved for patients with adult-onset RRMS, particularly therapies with known anti-inflammatory effects as demonstrated 
by reduction in clinical relapses and MRI accrual of new lesions. ${ }^{39}$ The rationale for this strategy is based on data showing that pediatric-onset MS is associated with an MRI burden of disease at least as great as that seen in adults with MS, ${ }^{8,40}$ if not even higher. ${ }^{7}$ The presence of at least 3 of 4 Barkhof MRI criteria at the onset of MS signs is predictive of early relapse after a diagnosis of MS in children. ${ }^{41}$ Therefore, it is reasonable to assume that MRI markers can have the same sensitivity for detecting disease activity in children as in the adult population. Furthermore, pediatric-onset MS is associated with a higher relapse rate frequency early in the disease relative to adult-onset MS, ${ }^{42}$ and given that in adults accrual of new lesions is associated with higher relapse rates, it is reasonable to implicate accrual of new MRI lesions as a surrogate for disease activity in the pediatric MS population. A recent study estimated sample sizes for pediatric MS trials using new T2 lesions compared to clinical (relapse rate) outcomes as the primary endpoint ${ }^{11}$ and showed a great advantage of MRI markers in reducing the size and duration of trials.

CONCLUSIONS The onset of MS during childhood affects not only established neural networks but also connections that are actively maturing. MRI measures provide a window into these processes through quantification of the development of structural pathways as well as the potential loss of such pathways or their cortical or subcortical connections. Linking such analyses with patient-relevant outcomes such as cognitive and behavioral health, social maturation, and prediction of future disability is a key area for future research. More-advanced analysis on 3T MRI and the very recent access to 7T MRI will provide information on cortical pathology in pediatric MS. Although initial work has suggested that cortical lesions are relatively infrequent ${ }^{43}$ and not a major contributory factor to cognitive function in patients with pediatric $\mathrm{MS},{ }^{44}$ larger studies are required to further explore the prevalence and accrual rate of cortical pathology in pediatric MS and the clinical importance of cortical lesions in patients in whom they do occur. The demonstration that MRI lesions are a valid surrogate for relapses in adult populations ${ }^{34}$ supports the use of MRI variables as primary endpoints in phase III trials for children with MSa key issue given the rarity of MS onset in childhood and adolescence and the feasibility of large clinical trials in this population. Finally, MRI serves as an important tool to monitor disease activity in MS. The emerging concept of "no evidence of disease activity" as a therapeutic goal in adult-onset MS therapeutics requires evaluation in pediatric MS, balancing therapeutic efficacy, mechanisms of action, and risk.

\section{AUTHOR CONTRIBUTIONS}

Brenda Banwell: drafting/revising the manuscript, study concept or design, analysis or interpretation of data. Douglas L. Arnold: drafting/ revising the manuscript. Jan-Mendelt Tillema: drafting/revising the manuscript. Maria A. Rocca: drafting/revising the manuscript. Massimo Filippi: drafting/revising the manuscript, study concept or design, analysis or interpretation of data. Bianca Weinstock-Guttman: drafting/revising the manuscript. Robert Zivadinov: drafting/revising the manuscript, study concept or design, analysis or interpretation of data. Maria Pia Sormani: drafting/revising the manuscript, study concept or design, analysis or interpretation of data. All authors accept responsibility for conduct of research and will give final approval.

\section{STUDY FUNDING}

This supplement is made possible by funding from the MS Cure Fund, Danish MS Society, German MS Society, Italian MS Association, MS International Federation, MS Research Foundation (Netherlands), National MS Society (USA) and Swiss MS Society.

\section{DISCLOSURE}

B. Banwell serves as a consultant for Novartis and as an editor for Multiple Sclerosis and Related Disorders. D. Arnold has consulted for Acorda Therapeutics, Biogen, EMD Serono, Genentech, Genzyme, GlaxoSmithKline, MedImmune, Mitsubishi, Novartis, Opexa Therapeutics, Receptos, Roche, Sanofi-Aventis, and Teva; has an equity interest in NeuroRx; and receives research support from Novartis and Biogen. J.-M. Tillema receives grant support from NIH (KL2TR000136-09). M. Rocca received speakers' honoraria from Biogen Idec, NOVARTIS, Genzyme, and ExCemed and receives research support from the Italian Ministry of Health and Fondazione Italiana Sclerosi Multipla. M. Filippi serves on scientific advisory boards for Teva Pharmaceutical Industries; has received compensation for consulting services and/or speaking activities from Biogen Idec, Excemed, Novartis, and Teva Pharmaceutical Industries; and receives research support from Biogen Idec, Teva Pharmaceutical Industries, Novartis, Italian Ministry of Health, Fondazione Italiana Sclerosi Multipla, Cure PSP, Alzheimer's Drug Discovery Foundation (ADDF), the Jacques and Gloria Gossweiler Foundation (Switzerland), and ARiSLA (Fondazione Italiana di Ricerca per la SLA). B. Weinstock-Guttman has participated in speakers' bureaus and served as a consultant for Biogen Idec, Teva Neuroscience, EMD Serono, Novartis, Genzyme \& Sanofi, Acorda Therapeutics, Inc., and Genentech. Dr. Weinstock-Guttman has received grant/research support from the agencies listed in the previous sentence as well as Questcor Pharmaceuticals, Inc., NMSS, NYSTEM, NIH, and ARMS foundation. She serves on the editorial board for BMJ Neurology, Journal of International MS, and CNS Drugs. R. Zivadinov received personal compensation from Teva Pharmaceuticals, Biogen Idec, EMD Serono, Novartis, Claret Medical, and Genzyme for speaking and consultant fees. Dr. Zivadinov received financial support for research activities from Biogen Idec, Teva Pharmaceuticals, Novartis, Claret Medical, Intekrin-Coherus, and Genzyme. Dr. Zivadinov serves on the editorial board of Journal of Alzheimer Disease, BMC Medicine, BMC Neurology, BioMed Research International, Vein and Lymphatics, and Clinical CNS Drugs. He is Treasurer and Executive Director of International Society for Neurovascular Disease. M. Sormani received consulting fees from Novartis, Biogen, TEVA, Merck Serono, Genzyme, Roche, and Synthon. Go to Neurology.org for full disclosures.

Received August 26, 2015. Accepted in final form February 8, 2016.

\section{REFERENCES}

1. Callen DJ, Shroff MM, Branson HM, et al. Role of MRI in the differentiation of ADEM from MS in children. Neurology 2009;72:968-973.

2. Verhey LH, Branson HM, Shroff MM, et al. MRI parameters for prediction of multiple sclerosis diagnosis in children with acute CNS demyelination: a prospective national cohort study. Lancet Neurol 2011;10: 1065-1073. 
3. Deiva K, Mahlaoui N, Beaudonnet F, et al. CNS involvement at the onset of primary hemophagocytic lymphohistiocytosis. Neurology 2012;78:1150-1156.

4. Polman $\mathrm{CH}$, Reingold SC, Banwell B, et al. Diagnostic criteria for multiple sclerosis: 2010 revisions to the McDonald criteria. Ann Neurol 2011;69:292-302.

5. Montalban X, Tintore M, Swanton J, et al. MRI criteria for MS in patients with clinically isolated syndromes. Neurology 2010;74:427-434.

6. Rovira A, Swanton J, Tintore M, et al. A single, early magnetic resonance imaging study in the diagnosis of multiple sclerosis. Arch Neurol 2009;66:587-592.

7. Waubant E, Chabas D, Okuda DT, et al. Difference in disease burden and activity in pediatric patients on brain magnetic resonance imaging at time of multiple sclerosis onset vs adults. Arch Neurol 2009;66:967-971.

8. Yeh EA, Weinstock-Guttman B, Ramanathan M, et al. Magnetic resonance imaging characteristics of children and adults with paediatric-onset multiple sclerosis. Brain 2009;132:3392-3400.

9. Banwell B, Shroff M, Ness J, et al. MRI features of pediatric multiple sclerosis. Neurology 2007;68:S46-S53.

10. Chabas D, Castillo-Trivino T, Mowry EM, Strober JB, Glenn OA, Waubant E. Vanishing MS T2-bright lesions before puberty: a distinct MRI phenotype? Neurology 2008;71:1090-1093.

11. Verhey LH, Signori A, Arnold DL, et al. Clinical and MRI activity as determinants of sample size for pediatric multiple sclerosis trials. Neurology 2013;81:1215-1221.

12. Bigi S, Marrie RA, Verhey L, Yeh EA, Banwell B. 2010 McDonald criteria in a pediatric cohort: is positivity at onset associated with a more aggressive multiple sclerosis course? Mult Scler 2013;19:1359-1362.

13. Hummel HM, Bruck W, Dreha-Kulaczewski S, Gartner J, Wuerfel J. Pediatric onset multiple sclerosis: McDonald criteria 2010 and the contribution of spinal cord MRI. Mult Scler 2013;19:1330-1335.

14. Sadaka Y, Verhey LH, Shroff MM, et al. 2010 McDonald criteria for diagnosing pediatric multiple sclerosis. Ann Neurol 2012;72:211-223.

15. Tantsis EM, Prelog K, Brilot F, Dale RC. Risk of multiple sclerosis after a first demyelinating syndrome in an Australian Paediatric cohort: clinical, radiological features and application of the McDonald 2010 MRI criteria. Mult Scler 2013;19:1749-1759.

16. Kornek B, Schmitl B, Vass K, et al. Evaluation of the 2010 McDonald multiple sclerosis criteria in children with a clinically isolated syndrome. Mult Scler 2012;18:1768-1774.

17. Williams MT, Tapos DO, Juhasz C. Use of the 2010 McDonald criteria can facilitate early diagnosis of pediatric multiple sclerosis in a predominantly black cohort. Pediatr Neurol 2014;51:826-830.

18. Krupp LB, Tardieu M, Amato MP, et al. International Pediatric Multiple Sclerosis Study Group criteria for pediatric multiple sclerosis and immune-mediated central nervous system demyelinating disorders: revisions to the 2007 definitions. Mult Scler 2013;19:1261-1267.

19. Verhey LH, Branson HM, Makhija M, Shroff M, Banwell B. Magnetic resonance imaging features of the spinal cord in pediatric multiple sclerosis: a preliminary study. Neuroradiology 2010;52:1153-1162.

20. Banwell B, Tenembaum S, Lennon VA, et al. Neuromyelitis optica-IgG in childhood inflammatory demyelinating CNS disorders. Neurology 2008;70:344-352.
21. Zecca C, Disanto G, Sormani MP, et al. Relevance of asymptomatic spinal MRI lesions in patients with multiple sclerosis. Mult Scler Epub 2015 Oct 12.

22. Wilejto M, Shroff M, Buncic JR, Kennedy J, Goia C, Banwell B. The clinical features, MRI findings, and outcome of optic neuritis in children. Neurology 2006;67: 258-262.

23. Waldman AT, Hiremath G, Avery RA, et al. Monocular and binocular low-contrast visual acuity and optical coherence tomography in pediatric multiple sclerosis. Mult Scler Relat Disord 2013;3:326-334.

24. Yeh EA, Weinstock-Guttman B, Lincoff N, et al. Retinal nerve fiber thickness in inflammatory demyelinating diseases of childhood onset. Mult Scler 2009;15:802-810.

25. Schiffmann R, van der Knaap MS. Invited article: an MRIbased approach to the diagnosis of white matter disorders. Neurology 2009;72:750-759.

26. Parikh S, Bernard G, Leventer RJ, et al. A clinical approach to the diagnosis of patients with leukodystrophies and genetic leukoencephelopathies. Mol Genet Metab 2015;114:501-515.

27. Evans AC, Frank JA, Antel J, Miller DH. The role of MRI in clinical trials of multiple sclerosis: comparison of image processing techniques. Ann Neurol 1997;41:125-132.

28. Sicotte NL, Voskuhl RR, Bouvier S, Klutch R, Cohen MS, Mazziotta JC. Comparison of multiple sclerosis lesions at 1.5 and 3.0 Tesla. Invest Radiol 2003;38: 423-427.

29. Wattjes MP, Lutterbey GG, Harzheim M, et al. Higher sensitivity in the detection of inflammatory brain lesions in patients with clinically isolated syndromes suggestive of multiple sclerosis using high field MRI: an intraindividual comparison of $1.5 \mathrm{~T}$ with $3.0 \mathrm{~T}$. Eur Radiol 2006;16: 2067-2073.

30. Chitnis T, Tenembaum S, Banwell B, et al. Consensus statement: evaluation of new and existing therapeutics for pediatric multiple sclerosis. Mult Scler 2012;18: 116-127.

31. McDonald RJ, McDonald JS, Kallmes DF, et al. Intracranial gadolinium deposition after contrast-enhanced MR imaging. Radiology 2015;275:772-782.

32. Kanda T, Fukusato T, Matsuda M, et al. Gadoliniumbased contrast agent accumulates in the brain even in subjects without severe renal dysfunction: evaluation of autopsy brain specimens with inductively coupled plasma mass spectroscopy. Radiology 2015;276:228-232.

33. Radbruch A, Weberling LD, Kieslich PJ, et al. Gadolinium retention in the dentate nucleus and globus pallidus is dependent on the class of contrast agent. Radiology 2015;275:783-791.

34. Sormani MP, Bonzano L, Roccatagliata L, Cutter GR, Mancardi GL, Bruzzi P. Magnetic resonance imaging as a potential surrogate for relapses in multiple sclerosis: a meta-analytic approach. Ann Neurol 2009;65:268-275.

35. Kerbrat A, Aubert-Broche B, Fonov V, et al. Reduced head and brain size for age and disproportionately smaller thalami in child-onset MS. Neurology 2012;78:194-201.

36. Aubert-Broche B, Fonov V, Narayanan S, et al. Onset of multiple sclerosis before adulthood leads to failure of ageexpected brain growth. Neurology 2014;83:2140-2146.

37. Sormani MP, Stubinski B, Cornelisse P, Rocak S, Li D, De SN. Magnetic resonance active lesions as individuallevel surrogate for relapses in multiple sclerosis. Mult Scler 2011;17:541-549. 
38. Sormani MP, Li DK, Bruzzi P, et al. Combined MR lesions and relapses as a surrogate for disability in multiple sclerosis. Neurology 2011;77:1684-1690.

39. Sormani MP, Bruzzi P. MRI lesions as a surrogate for relapses in multiple sclerosis: a meta-analysis of randomised trials. Lancet Neurol 2013;12:669-676.

40. Ghassemi R, Narayanan S, Banwell B, Sled JG, Shroff M, Arnold DL. Quantitative determination of regional lesion volume and distribution in children and adults with relapsing-remitting multiple sclerosis. PLoS One 2014; 9:e85741.

41. Tenembaum SN. Ethical challenges in paediatric clinical trials in multiple sclerosis. Ther Adv Neurol Disord 2012; 5:139-146.

42. Gorman MP, Healy BC, Polgar-Turcsanyi M, Chitnis T. Increased relapse rate in pediatric-onset compared with adult-onset multiple sclerosis. Arch Neurol 2009;66: 54-59.

43. Absinta M, Rocca MA, Moiola L, et al. Cortical lesions in children with multiple sclerosis. Neurology 2011;76: 910-913.

44. Rocca MA, De ME, Amato MP, et al. Cognitive impairment in paediatric multiple sclerosis patients is not related to cortical lesions. Mult Scler 2015;21:956-959.

45. Mikaeloff Y, Adamsbaum C, Husson B, et al. MRI prognostic factors for relapse after acute CNS inflammatory demyelination in childhood. Brain 2004;127:1942-1947.

46. De Jager PL, Jia X, Wang J, et al. Meta-analysis of genome scans and replication identify CD6, IRF8 and TNFRSF1A as new multiple sclerosis susceptibility loci. Nat Genet 2009;41:776-782.

47. Huppke P, Rostasy K, Karenfort M, et al. Acute disseminated encephalomyelitis followed by recurrent or monophasic optic neuritis in pediatric patients. Mult Scler 2013; 19:941-946.

48. Absoud M, Lim MJ, Appleton R, et al. Paediatric neuromyelitis optica: clinical, MRI of the brain and prognostic features. J Neurol Neurosurg Psychiatry 2015;86: 470-472.

49. Benseler SM, Silverman E, Aviv RI, et al. Primary central nervous system vasculitis in children. Arthritis Rheum 2006;54:1291-1297.

50. Benseler S, Schneider R. Central nervous system vasculitis in children. Curr Opin Rheumatol 2004;16:43-50.

51. Karaoglu P, Topcu Y, Bayram E, et al. Severe neurologic involvement of Degos disease in a pediatric patient. J Child Neurol 2014;29:550-554.

52. Amato C, Ferri R, Elia M, et al. Nervous system involvement in Degos disease. AJNR Am J Neuroradiol 2005;26: 646-649.

53. Burrow JN, Blumbergs PC, Iyer PV, Hallpike JF. Kohlmeier-Degos disease: a multisystem vasculopathy with progressive cerebral infarction. Aust N Z J Med 1991;21:49-51.

54. Tzoulis C, Engelsen BA, Telstad W, et al. The spectrum of clinical disease caused by the A467T and W748S POLG mutations: a study of 26 cases. Brain 2006;129: 1685-1692.

55. Wolf NI, Toro C, Kister I, et al. DARS-associated leukoencephalopathy can mimic a steroid-responsive neuroinflammatory disorder. Neurology 2015;84:226-230.

56. Kassem H, Wafaie A, Abdelfattah S, Farid T. Leukoencephalopathy with brainstem and spinal cord involvement and lactate elevation (LBSL): assessment of the involved white matter tracts by MRI. Eur J Radiol 2014;83: 191-196.

57. van der Knaap MS, Salomons GS. Leukoencephalopathy with brain stem and spinal cord involvement and lactate elevation. In: Pagon RA, Adam MP, Ardinger HH, et al, eds. GeneReviews. Seattle: University of Washington. Available at: http://www.ncbi.nlm. nih.gov/books/NBK43417/. Published May 25, 2010. Updated February 12, 2015.

58. Aubert-Broche B, Fonov V, Ghassemi R, et al. Regional brain atrophy in children with multiple sclerosis. Neuroimage 2011;58:409-415.

59. Aubert-Broche B, Fonov VS, Garcia-Lorenzo D, et al. A new method for structural volume analysis of longitudinal brain MRI data and its application in studying the growth trajectories of anatomical brain structures in childhood. Neuroimage 2013;82:393-402.

60. Brown RA, Narayanan S, Banwell B, Arnold DL. Magnetization transfer ratio recovery in new lesions decreases during adolescence in pediatric-onset multiple sclerosis patients. Neuroimage Clin 2014;6:237-242.

61. Mezzapesa DM, Rocca MA, Falini A, et al. A preliminary diffusion tensor and magnetization transfer magnetic resonance imaging study of early-onset multiple sclerosis. Arch Neurol 2004;61:366-368.

62. Tortorella P, Rocca MA, Mezzapesa DM, et al. MRI quantification of gray and white matter damage in patients with early-onset multiple sclerosis. J Neurol 2006;253: 903-907.

63. Rocca MA, Absinta M, Moiola L, et al. Functional and structural connectivity of the motor network in pediatric and adult-onset relapsing-remitting multiple sclerosis. Radiology 2010;254:541-550.

64. Vishwas MS, Chitnis T, Pienaar R, Healy BC, Grant PE. Tract-based analysis of callosal, projection, and association pathways in pediatric patients with multiple sclerosis: a preliminary study. AJNR Am J Neuroradiol 2010;31:121-128.

65. Absinta M, Rocca MA, Moiola L, et al. Brain macro- and microscopic damage in patients with paediatric MS. J Neurol Neurosurg Psychiatry 2010;81:1357-1362.

66. Aliotta R, Cox JL, Donohue K, et al. Tract-based spatial statistics analysis of diffusion-tensor imaging data in pediatric- and adult-onset multiple sclerosis. Hum Brain Mapp 2014;35:53-60.

67. Vishwas MS, Healy BC, Pienaar R, Gorman MP, Grant PE, Chitnis T. Diffusion tensor analysis of pediatric multiple sclerosis and clinically isolated syndromes. AJNR Am J Neuroradiol 2013;34:417-423.

68. Rocca MA, Absinta M, Ghezzi A, Moiola L, Comi G, Filippi M. Is a preserved functional reserve a mechanism limiting clinical impairment in pediatric MS patients? Hum Brain Mapp 2009;30:2844-2851.

69. Rocca MA, Absinta M, Amato MP, et al. Posterior brain damage and cognitive impairment in pediatric multiple sclerosis. Neurology 2014;82:1314-1321.

70. Rocca MA, Valsasina P, Absinta M, et al. Intranetwork and internetwork functional connectivity abnormalities in pediatric multiple sclerosis. Hum Brain Mapp 2014;35: 4180-4192.

71. Akbar N, Till C, Sled JG, et al. Altered resting-state functional connectivity in cognitively preserved pediatric-onset MS patients and relationship to structural damage and cognitive performance. Mult Scler Epub 2015 Sep 11. 


\title{
Neurology
}

\author{
MRI in the evaluation of pediatric multiple sclerosis \\ Brenda Banwell, Douglas L. Arnold, Jan-Mendelt Tillema, et al. \\ Neurology 2016;87;S88-S96 \\ DOI 10.1212/WNL.0000000000002787
}

This information is current as of August 29, 2016

\section{Updated Information \& Services}

\section{References}

Citations

Subspecialty Collections

\section{Permissions \& Licensing}

Reprints including high resolution figures, can be found at: http://n.neurology.org/content/87/9_Supplement_2/S88.full

This article cites 68 articles, 4 of which you can access for free at: http://n.neurology.org/content/87/9_Supplement_2/S88.full\#ref-list-1

This article has been cited by 2 HighWire-hosted articles: http://n.neurology.org/content/87/9_Supplement_2/S88.full\#\#otherartic les

This article, along with others on similar topics, appears in the following collection(s):

All Demyelinating disease (CNS)

http://n.neurology.org/cgi/collection/all_demyelinating_disease_cns All Pediatric

http://n.neurology.org/cgi/collection/all_pediatric

MRI

http://n.neurology.org/cgi/collection/mri

Multiple sclerosis

http://n.neurology.org/cgi/collection/multiple_sclerosis

Information about reproducing this article in parts (figures,tables) or in its entirety can be found online at:

http://www.neurology.org/about/about_the_journal\#permissions

Information about ordering reprints can be found online: http://n.neurology.org/subscribers/advertise

Neurology ${ }^{\circledR}$ is the official journal of the American Academy of Neurology. Published continuously since 1951, it is now a weekly with 48 issues per year. Copyright @ 2016 American Academy of Neurology. All rights reserved. Print ISSN: 0028-3878. Online ISSN: 1526-632X.

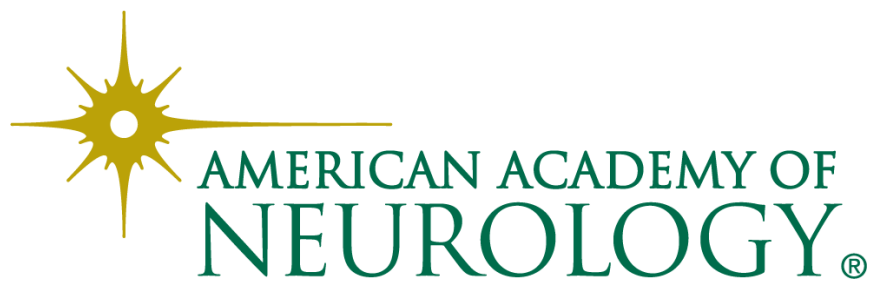

